\title{
POWER QUALITY IMPROVEMENT IN POWER SYSTEM BY USING SVPWM BASED STATIC SYNCHRONOUS SERIES COMPENSATOR
}

\author{
Vicky T. Kullarkar ${ }^{1}$ and Vinod K. Chandrakar ${ }^{2}$
}

\begin{abstract}
Power quality improvement is an important issue in power system. Flexible AC Transmission (FACTS) devices are commonly used for solving problems related to power quality and improving it. In this paper a synchronous static series compensator (SSSC) is used for control and modulation of power flow in a transmission line. The Pulse Width Modulation (PWM) and SVPWM control techniques are employed in SSSC. The active performance of SSSC is evaluated using Matlab/Simulink environment. The simulation results validate that the power quality is enhanced properly using SSSC.
\end{abstract}

Index Terms-Power Quality, FACTS, PWM, SVPWM, SSSC

\section{INTRODUCTION}

In power systems the utilization of electricity varies frequently so it is important to manage the flow of power in the system. Also, power quality has become an important issue for electricity consumers at all levels of usage. This may be due to non linear loads, sensitive equipment, network equipment etc. Therefore for the safe operation of the power system the new methods are needed. The introduction of FACTS devices help in obtaining both reliability and economic constrain. That is with the use of FACTS devices the power is delivered more economically utilizing the present transmission line avoiding the cost of using new transmission line and also generates more power. As known FACTS technology is a group of controllers that work coordinately with each other ensuring an efficient control over multiple system parameters.

The power system is nonlinear in nature, operating in continuously varying environment, i.e., loads, outputs, topology, operating parameters etc. The systems stability is based on the initial operating conditions and the nature of the disturbance that can be large or small when subjected to transient disturbance. The system must be able to function suitably under these conditions. Among the FACTS devices the synchronous static series compensator (SSSC) plays a key role in absorbing or generating reactive power from the transmission line. The SSSC controller comprises a VSC, a dc capacitor, a controller and a transformer. The VSCs are linked together by a transformer. The different configurations of a transformer and the number of valves are based on the required quality of ac waveforms which are generated by the SSSC. The VSC is connected in series with a transmission line permitting series compensation of the line.

The SSSC is similar to an ideal synchronous voltage source in generating three phase ac voltages at the variable's fundamental frequency, phase angle and controllable amplitude. And it is similar to synchronous compensator in generating or absorbing reactive power and real power from a power system with the replacement of energy storage device in the place of dc capacitor. The limitation of SSSC is exchange of only reactive power with the nearby ac system, ignoring the real power which is because of the small SSSC capacitor. This limitation can be achieved by replacing the dc capacitor with an energy storage system thus compensating for the resistance in transmission line.

\footnotetext{
${ }^{1}$ Department of Electrical Engineering G. H. Raisoni College of Engineering, Nagpur, Maharashtra, India

${ }^{2}$ Department of Electrical Engineering G. H. Raisoni College of Engineering, Nagpur, Maharashtra, India
} 
In this paper the study of power quality is done by using IEEE 9 bus system with 3 machines. To study the power quality non linear load is connected in the system at bus 5 as shown in Fig. 4. Non linear load used in this case is diode bridge rectifier, power quality gets reduced because of this non linear load and hence SSSC a FACTS device is used to improve the power quality with sinusoidal pulse width modulation and with space vector pulse width modulation techniques. Comparative study of both techniques is discussed in this paper.

\section{SSSC CONFIGURATION}

As depicted in Fig. 1 the SSSC consists of VSC, transformer and energy storage. The energy storage is involved in the exchange of both active and reactive power with the ac system which is determined by the phase displacement of the inserted voltage $V_{p q}$, and the transmission line current $I_{\text {line }}$. The output voltage and phase angle variation influences the flow of power in the transmission line.

As in Fig. 2 the SSSC can be operated in each of the four quadrants theoretically, but the injected voltage has limitations because of operating conditions in the power system in practical.

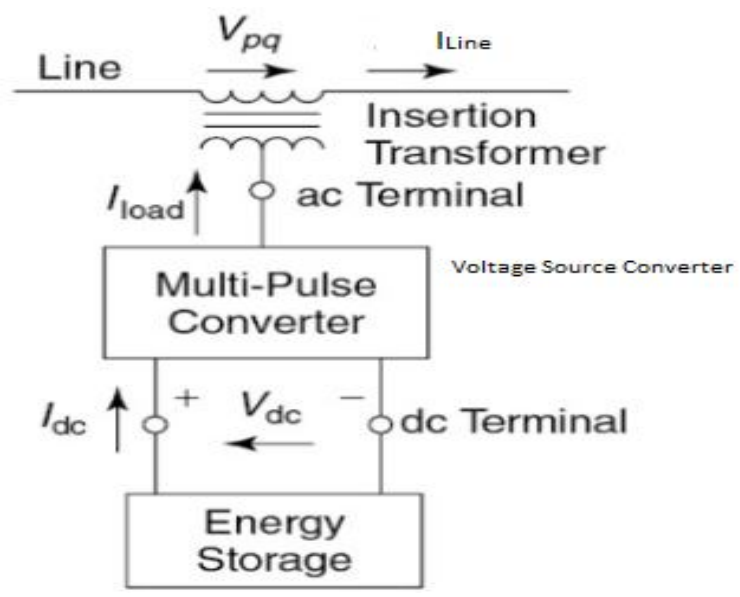

Figure 1. Functional model of SSSC.

The SSSC voltage injected is lagged the transmission line current by $90^{\circ}$ in capacitive mode. Here the SSSC resembles series capacitor with inconsistent capacitance $k X c$, i.e., $V_{p q}=j K X_{C} I_{\text {line }}$, where $\mathrm{k}$ is a variable. With this the total line reactance is decreased and the impedance voltage is increased, thus increasing the transmitted power and line currents as depicted in Fig.3.

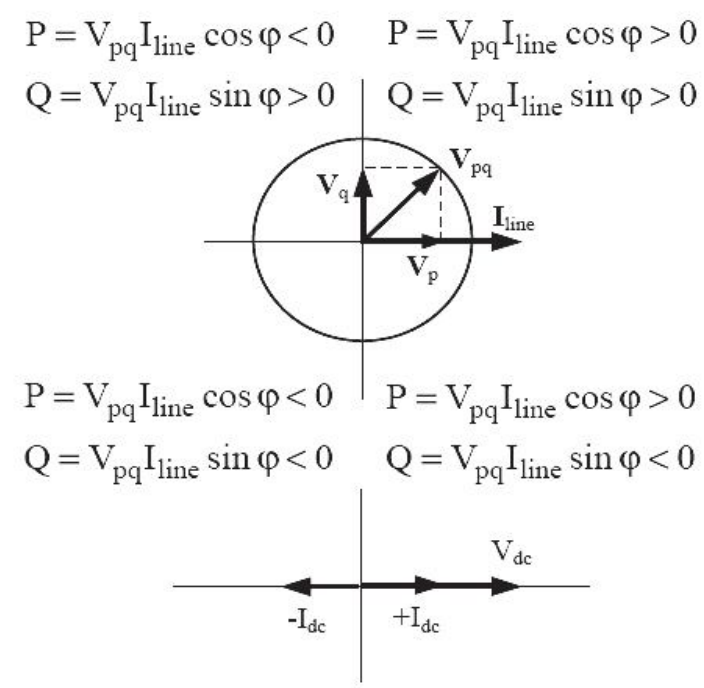

Figure 2. Phasor diagram of SSSC.

The reverse is occurred when the injected SSSC voltage is lagged by $180^{\circ}$ i.e., $-V_{p q}=j K X_{C} I_{l i n e}$, resulting in increase in transmission line reactance and decrease in transmitted power and line current. The reversal of operation from capacitive mode to inductive mode can increase and decrease the transmission line power flow. 
In case of inductive mode, the voltage drop formed across the line reactance and the series injected voltages are in phase, therefore series compensation is in proportion with the line reactance. If $V_{p q} \geq V_{\text {line }}$ the power flows in reverse, where $V_{p q}$ denotes the magnitude of the series inserted voltage and $V_{\text {line }}$ represents the voltage drop across the line, but SSSC is not probable for power reversal. Moreover if the SSSC controller rating is high, the raise or decline of the receiving end voltage is possible beyond or beneath the typical working voltage range of 0.95p.u. - 1.05 p.u, however in case of other system devices it is possible with negative consequences.

(a)

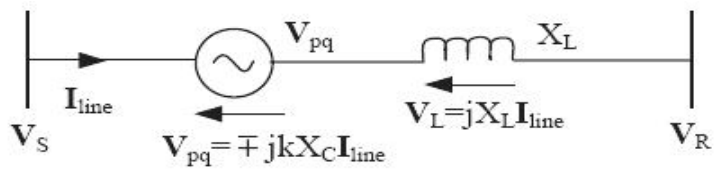

(b)

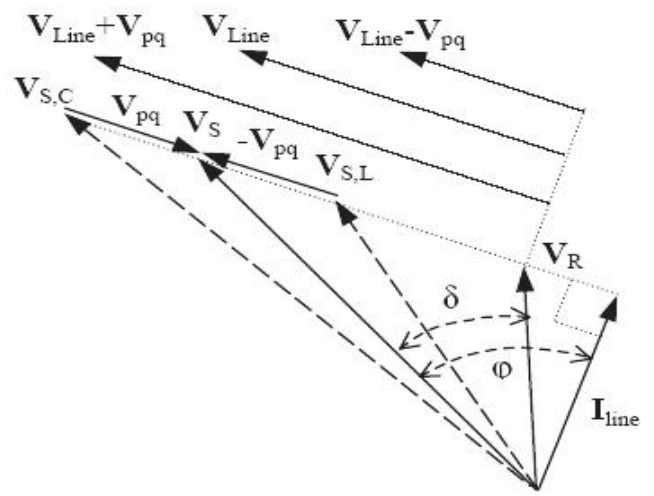

Figure 3. Series compensation by a SSSC.

The active power and the reactive power exchanged between the compensator and the transmission line is calculated as follows:

$$
\begin{aligned}
& P_{p q}=V_{p q \cdot} I_{\text {line }} \cos \square \\
& P_{p q}=V_{p q} I_{\text {line }} \sin \square
\end{aligned}
$$

where $\square$ denotes the angle between the transmission line current and the injected voltage, approximately $90^{\circ}$, indicates that the real power should be small than the reactive power. This is because the real power is used only to cover the losses, caused by the transformer windings and GTO valves switching, and to charge the dc capacitor, i.e.,

$$
p_{p q}=p_{d c}+p_{\text {losses }}
$$

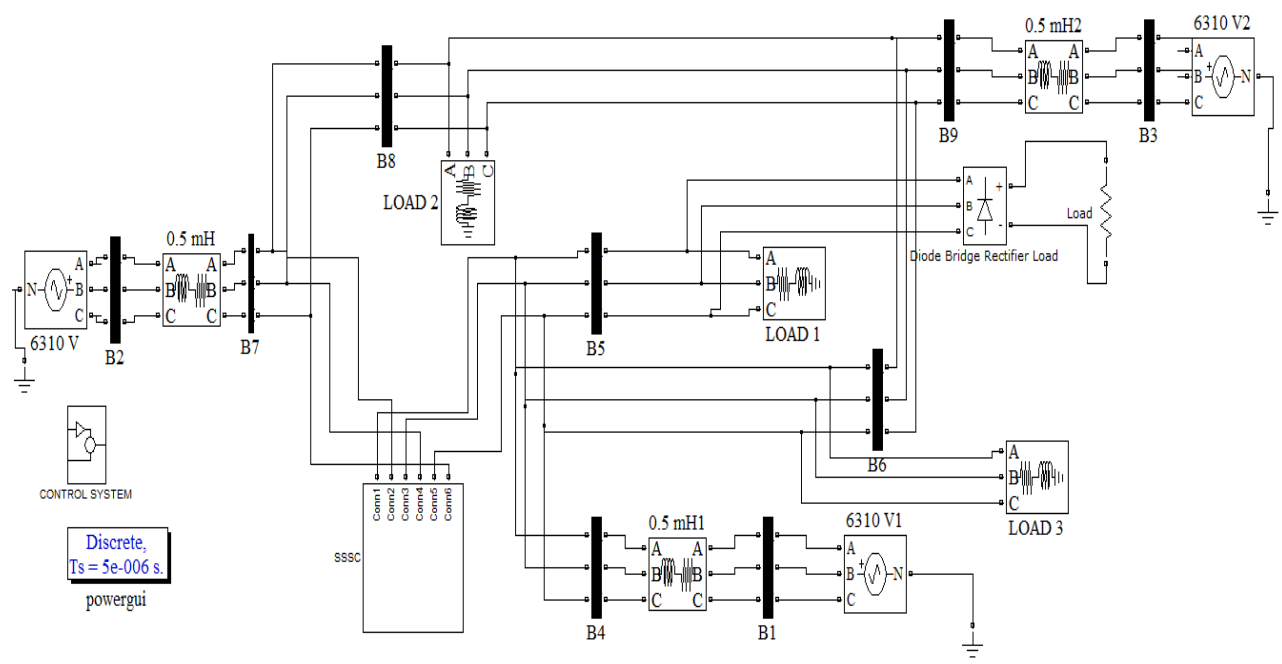

Figure 4. Multi machine system with SSSC.

The power quality is study in the following sequence :-

Case (I) :-As shown in fig.4. load is connected at bus 5. Simulation results are carried out for the system without connecting SSSC in the system and by using FFT analysis the total harmonic distortions in voltage and current were recorded. 
Case (II) :- In this case SSSC is connected in series with the transmission line as shown in fig.4. SSSC is connected in series with transmission line between the bus 5 and bus 7. In this case the diode bridge rectifier is kept connected at bus 5. Finally, with SSSC and with non linear load total harmonic distortions in voltage and current are measured by using FFT analysis. FFT analysis is carried out for SPWM SSSC and SVPWM SSSC respectively.

\section{CONTROL TECHNIQUES}

The PWM techniques that can be applied are

A) Sinusoidal Pulse Width Modulation Technique

B) Space Vector Pulse Width Modulation Technique

A) Sinusoidal pulse width modulation technique (SPWM)

The sinusoidal PWM switching scheme allows control of the magnitude and the frequency of the output voltage. Therefore, the input to the PWM inverters is an uncontrolled, essentially constant dc voltage source. This switching scheme results in harmonic voltage in the range of the switching frequency and higher, which can be easily filtered out. The scheme, in its simplified form, involves comparison of a high frequency triangular carrier voltage with a sinusoidal modulating signal that represents the desired fundamental component of the voltage waveform. The sinusoidal pulse width modulation technique waveform is shown in Fig.5.

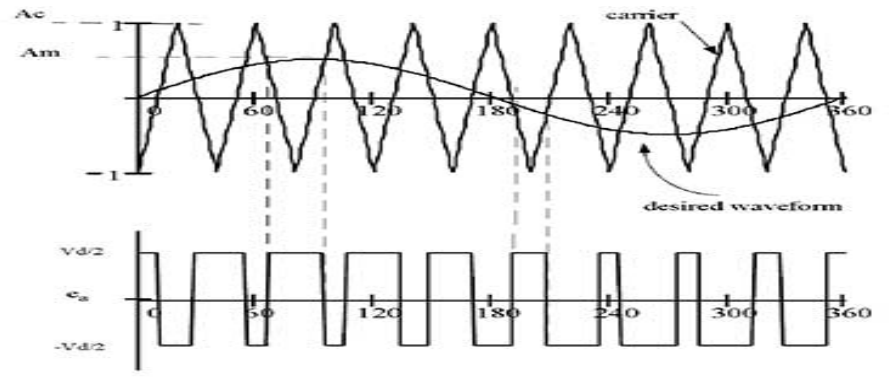

Figure 5. Sinusoidal PWM

B) Space vector pulse width modulation (SVPWM) with three levels inverter

Fig. 6 shows the diode-clamped inverter also called as the neutral point clamped (NPC) inverter. There are 12 power switching devices, 6 clamping diodes in the circuit. Of which 4 anti parallel diodes, 2 neutral clamping diodes and 4 IGBTs are contained in each arm. The bulk capacitors $\mathrm{C} 1$ and $\mathrm{C} 2$ are connected in series which are used in splitting the dc bus voltage into three voltage levels. The midpoint of $\mathrm{C} 1$ and $\mathrm{C} 2$ is called as neutral point.

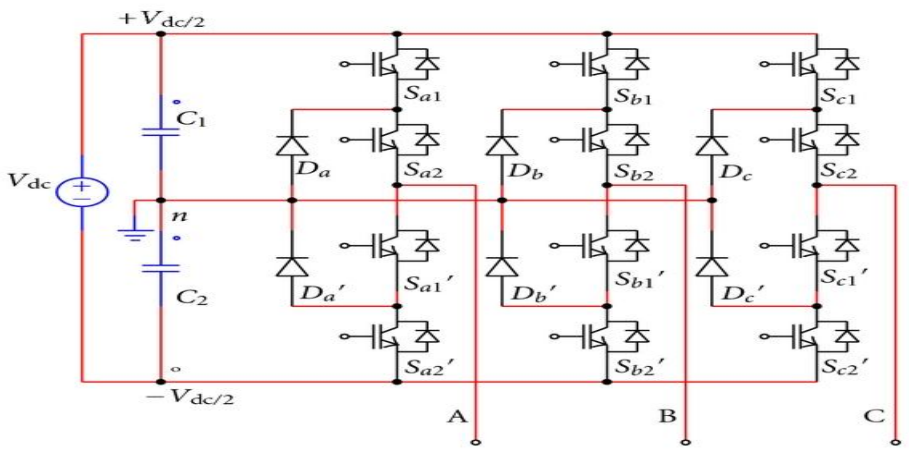

Figure 6. Diode clamped three levels inverter.

Table 1. Switching Configuration

\begin{tabular}{|c|c|c|}
\hline Switches on & Switches off & Output Voltage \\
\hline$Q_{1 A}, Q_{2 A}$ & $Q_{3 A}, Q_{4 A}$ & $+V_{D C}$ \\
\hline$Q_{2 A}, Q_{3 A}$ & $Q_{1 A,} Q_{4 A}$ & 0 \\
\hline
\end{tabular}




\begin{tabular}{|l|l|l|}
\hline$Q_{3 A}, Q_{4 A}$ & $Q_{1 A}, Q_{2 A}$ & $-V_{D C}$ \\
\hline
\end{tabular}

Space Vector Pulse Width Modulation (SVPWM)

SVM considers the inverter as a single unit which can be directed to eight unique states of which six are active states and two are zero states. A hexagon is formed by these vectors can be seen as six sectors spanning $60^{\circ}$ each. The switching operation between two closest active and zero vectors by SVPWM generates the reference vector representing the three phase sinusoidal voltage. The switching of inverter state accomplishes the modulation. The purpose of SVM, a digital modulation method, is to produce PWM load line voltages by correctly selecting the inverter switching states in each sampling period and to calculate the appropriate time period for each state. There are 6 (I-VI) sectors consisting 4 (1-4) regions as in Fig. 7 with switching states of all vectors.

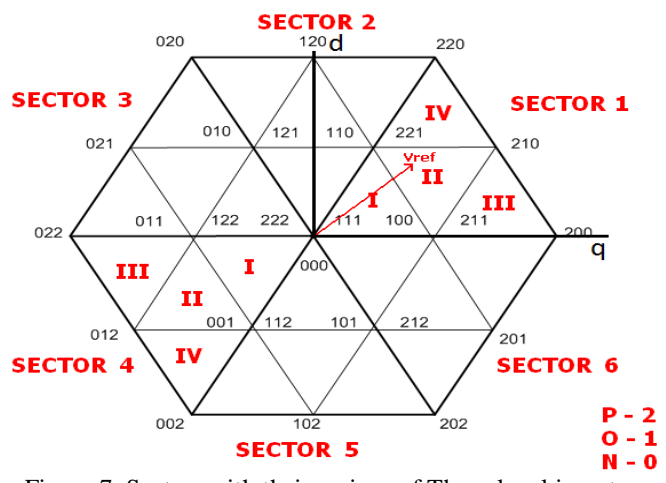

Figure 7. Sectors with their regions of Three-level inverter.

\section{SIMULATION RESULTS}

The performance of static synchronous series compensator (SSSC) using sinusoidal pulse width modulation (SPWM) and space vector pulse width modulation (SVPWM) is validated using Matlab/Simulink software.

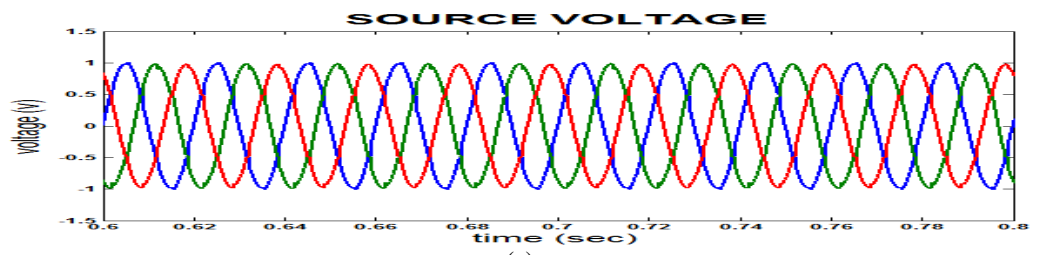

(a)

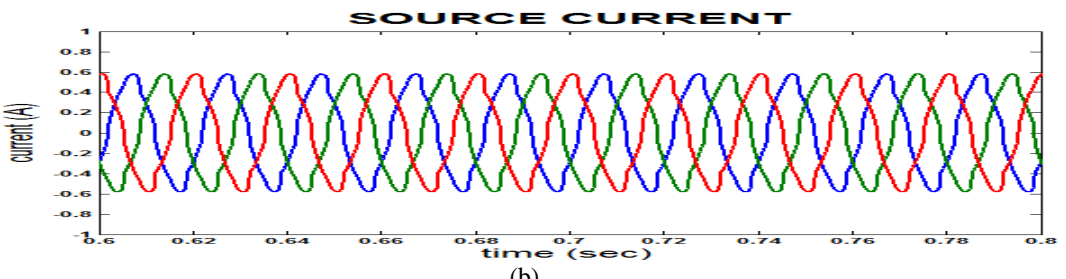

Figure 8. (a) Source voltage (b) Source current without SSSC.

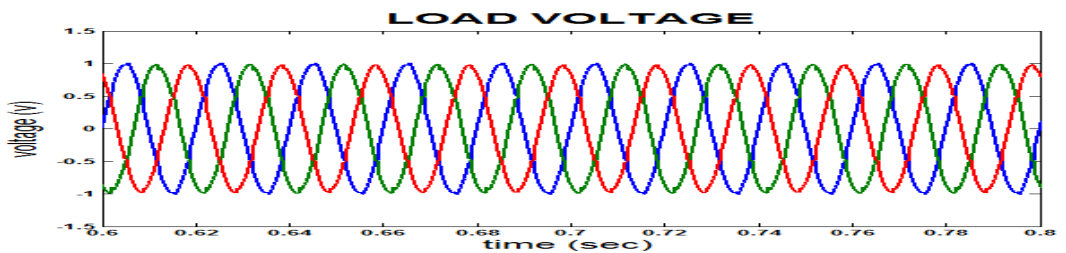

(a) 
Power Quality Improvement In Power System By Using Svpwm Based Static Synchronous Series Compensator

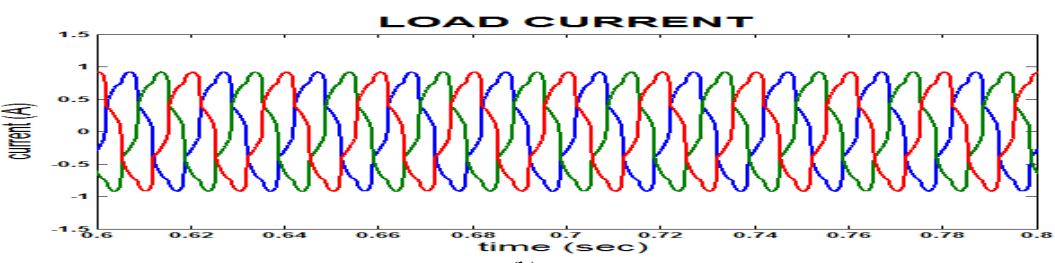

(b)

Figure 9. (a) Load voltage (b) Load current without SSSC.

Fig. 8 and Fig. 9 shows the source voltage, source current and load voltage, load current respectively without using SSSC. Hence, after observing the Fig. 9 and Fig. 10 it is clear that because of the non linear load voltage and current waveforms gets disturbed because of non linear load without SSSC.
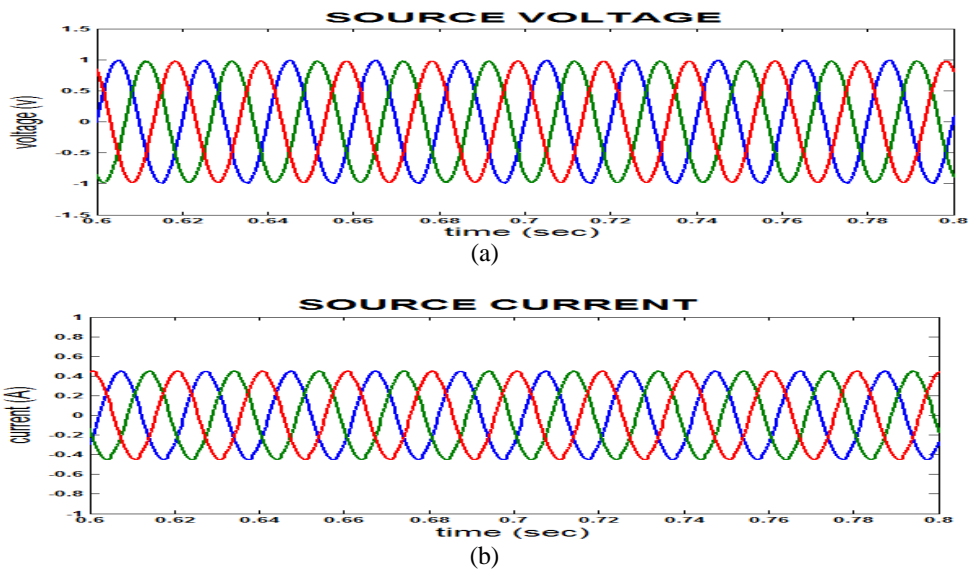

Figure 10. (a) Source voltage (b) Source current with SSSC

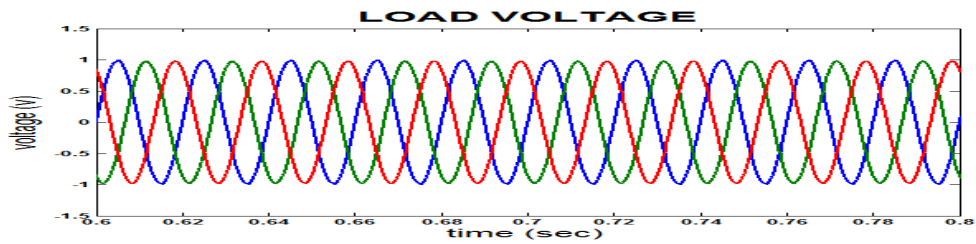

(a)

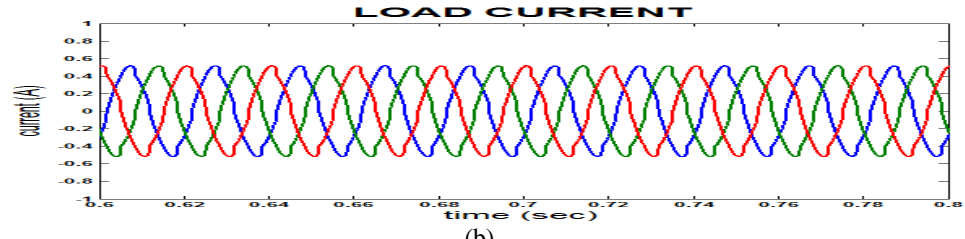

Figure 11. (a) Load voltage (b) Load current with SSSC.

Fig. 10 and Fig. 11 shows the source voltage, source current and load voltage, load current respectively by using SPWM based SSSC. Hence, after observing these simulation results it is clear that voltage and current waveform become smoother as compared to without SSSC. Hence by using the SSSC power quality gets improved.

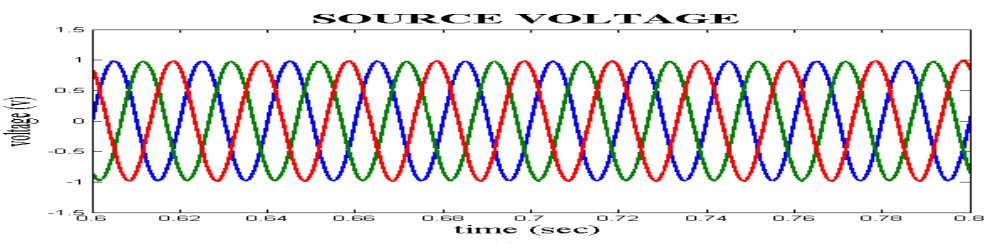

(a) 


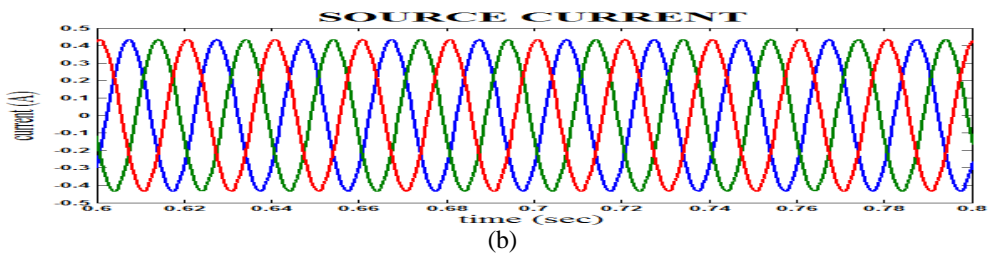

Figure 12. (a) Source voltage (b) Source current with SVPWM SSSC.

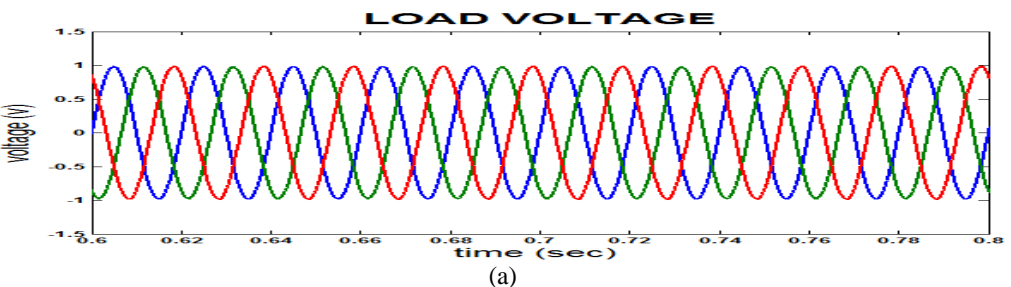

(a)

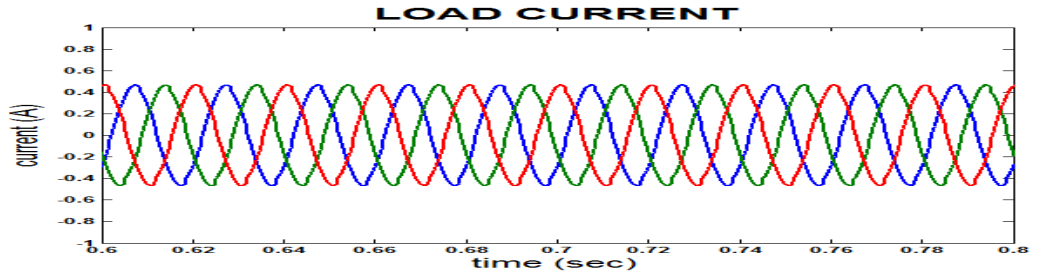

(b)

Figure 13. (a) Load voltage (b) Load current with SVPWM SSSC.

Fig. 12 and Fig. 13 shows the source voltage, source current and load voltage, load current respectively by using SVPWM based SSSC. Hence, from these simulation results it is clear that voltage and current waveform become smoother as compared to that of without SSSC and with SSSC. Hence by using the SVPWM based SSSC power quality gets improved. Therefore, by using this technique power quality problem in the power system can be overcome very efficiently.

\section{FAST FOURIER TRANSFORM (FFT) ANALYSIS FOR TOTAL HARMONIC DISTORTION (THD) MEASUREMENT}

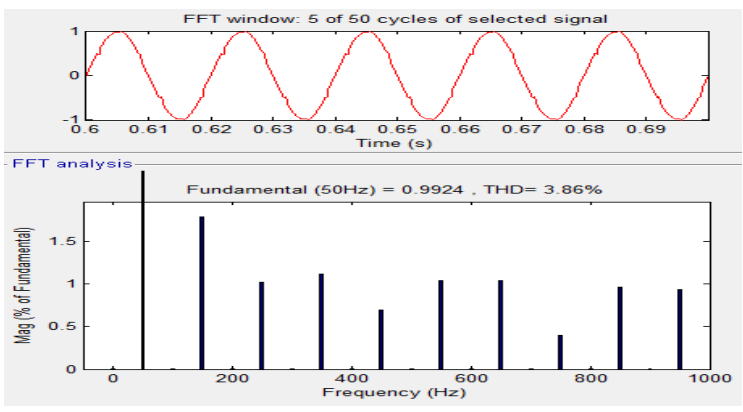

(a)

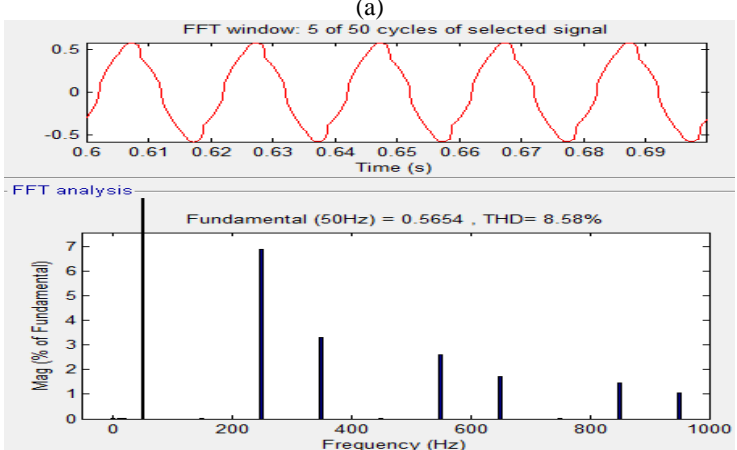

(b)

Figure 14. FFT analysis of (a) Source voltage (b) Source current-without SSSC 


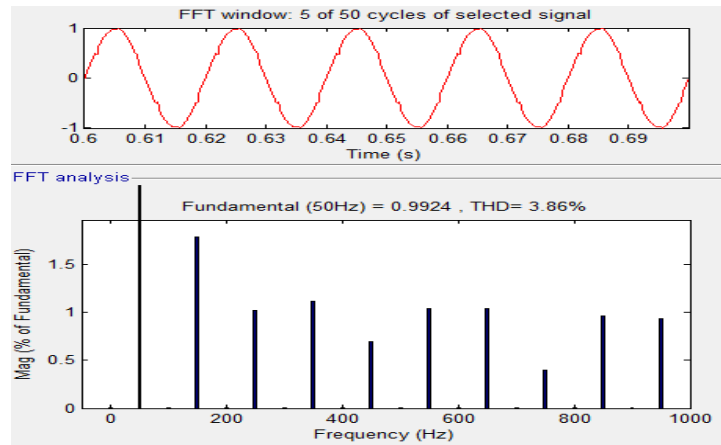

(a)

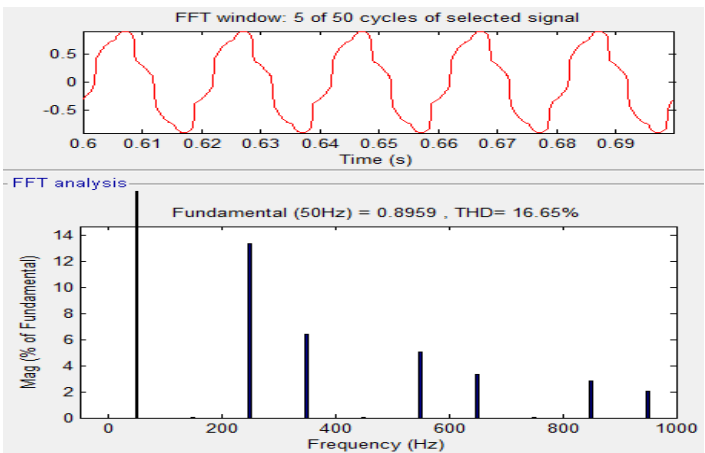

(b)

Figure 15. FFT analysis of (a) Load voltage (b) Load current -without SSSC.

Fig. 14 and Fig. 15 shows the FFT analysis results for source voltage, source current and load voltage, load current respectively without using SSSC. Hence, from FFT results the THDs observed for the source voltage, source current and load voltage, load current are 3.86\%, 8.58\%, 3.86\%, 16.65\% respectively. Form these results it is clear that more THDs are present in the current waveform as compared to the voltage waveform.

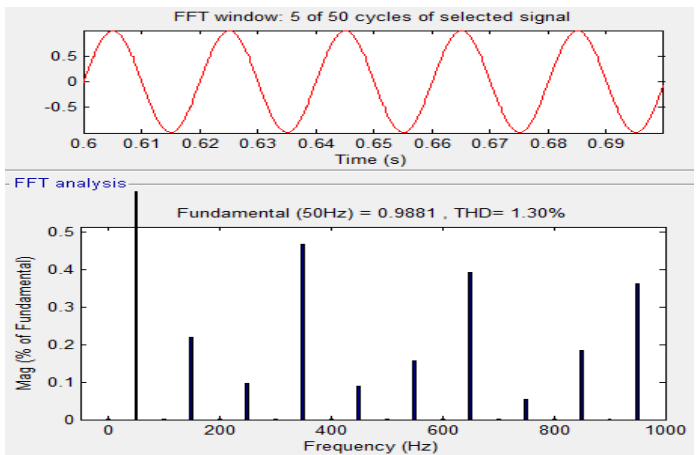

(a)

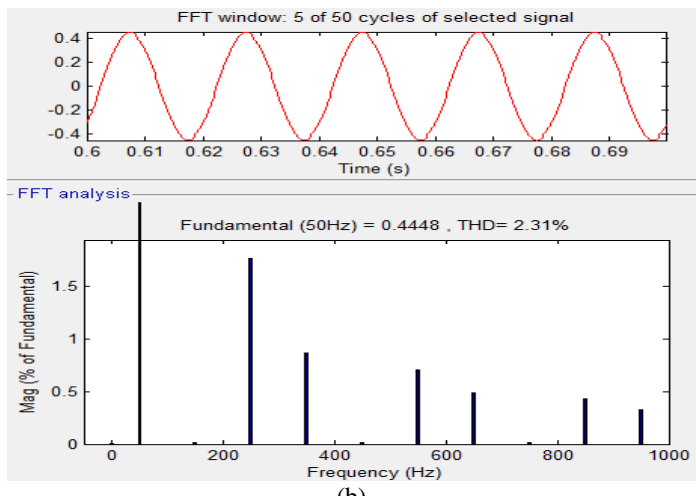

(b)

Figure 16. FFT analysis of (a) Source voltage (b) Source current with SSSC. 


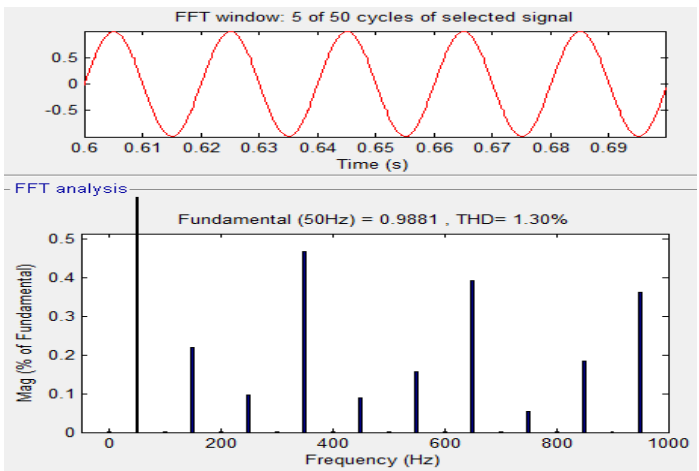

(a)

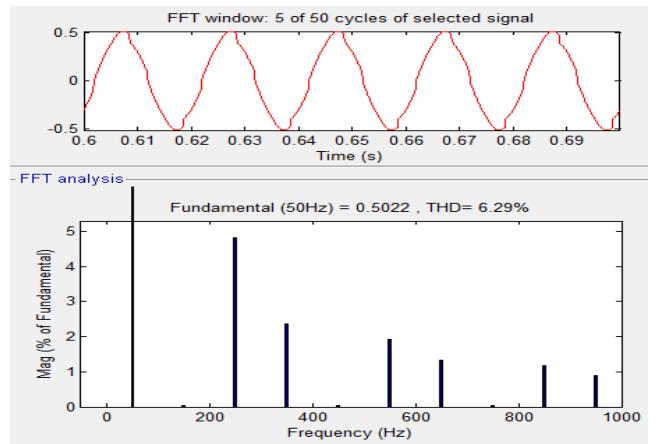

(b)

Figure 17. FFT analysis of (a) Load voltage (b) Load current with SSSC.

Fig. 16 and Fig. 17 shows the FFT analysis results for source voltage, source current and load voltage, load current respectively by using SPWM based SSSC. Hence, from FFT analysis results the THDs for the source voltage, source current and load voltage, load current are $1.30 \%, 2.31 \%, 1.30 \%, 6.29 \%$ respectively. From this it is clear that by using SSSC in the system distortions present in the voltage and current can be reduced that is harmonics present in the system can be reduced.

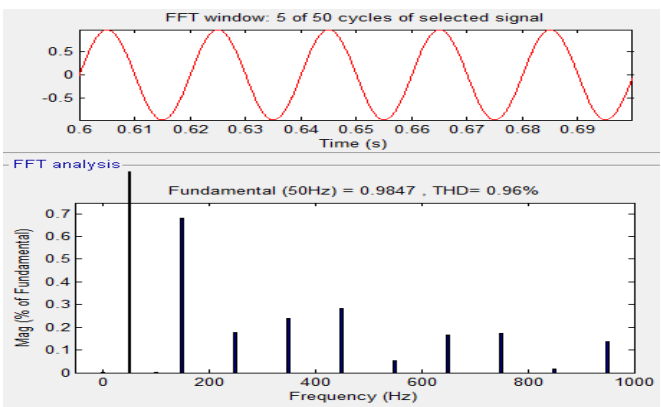

(a)

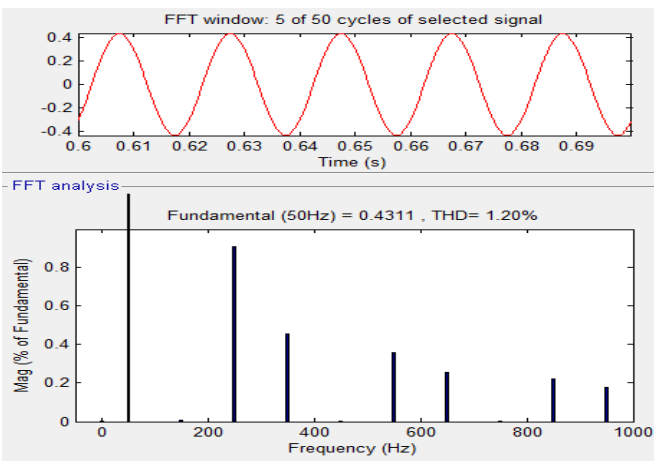

(b)

Figure 18. FFT analysis of (a) source voltage and (b) source current using SVPWM SSSC. 


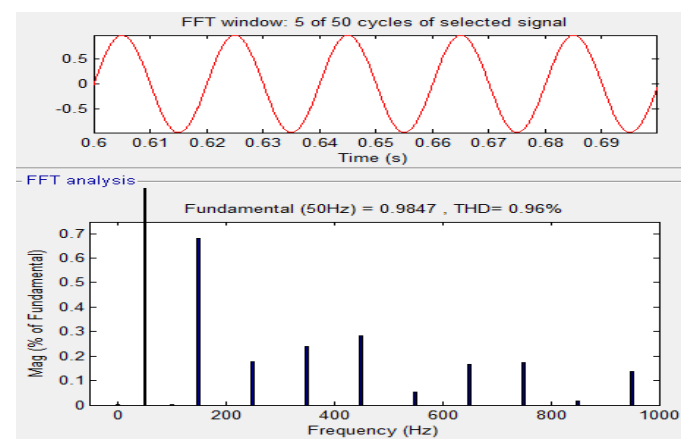

(a)

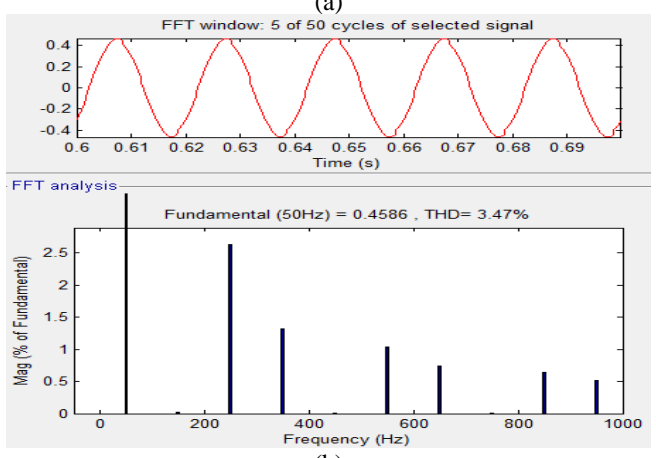

(b)

Figure 19. FFT analysis of (a) Load voltage and (b) Load current using SVPWM SSSC.

Fig. 18 and Fig. 19 shows the FFT analysis results for source voltage, source current and load voltage, load current respectively by using SVPWM based SSSC. Hence, from FFT analysis results the THDs for the source voltage, source current and load voltage, load current are $0.96 \%, 1.20 \%, 0.96 \%, 3.47 \%$ respectively. From this it is clear that by using SVPWM based SSSC the harmonics present in the system voltage and current can be reduced very effectively as compared to that of the system with SPWM based SSSC. The THD values are tabulated in the following table.

Table -2 Total Harmonic Distortion Analysis

\begin{tabular}{|c|c|c|c|c|}
\hline & $\begin{array}{c}\text { Source } \\
\text { Voltage }\end{array}$ & $\begin{array}{c}\text { Source } \\
\text { Current }\end{array}$ & $\begin{array}{c}\text { Load } \\
\text { Voltage }\end{array}$ & $\begin{array}{c}\text { Load } \\
\text { Current }\end{array}$ \\
\cline { 2 - 5 } THD (\%) & THD (\%) & THD (\%) & THD (\%) \\
\hline $\begin{array}{c}\text { Without } \\
\text { SSSC }\end{array}$ & 3.86 & 8.58 & 3.86 & 16.65 \\
\hline $\begin{array}{c}\text { SPWM } \\
\text { SSSC }\end{array}$ & 1.30 & 2.31 & 1.30 & 6.29 \\
\hline $\begin{array}{c}\text { SVPWM } \\
\text { SSSC }\end{array}$ & 0.96 & 1.20 & 0.96 & 3.47 \\
\hline
\end{tabular}

\section{CONCLUSION}

In this paper the problem of modulation and control of power flow in transmission line is carried out by using SSSC with PWM and SVPWM techniques. The performance of SSSC is validated using Matlab/Simulink software. Thus, simulation results and THD analysis shows that by using SVPWM based SSSC power quality gets improved more as compared to the SPWM based SSSC. Hence SVPWM technique proves better as compared to that of the SPWM technique for power quality improvement.

\section{REFERENCES}

[1] N.G. Hingorani and L. Gyugyi, "Understanding FATCS concepts andtechnology of flexible ac transmission system", New York, NY: IEEE press, 2000.

[2] “Static Synchronous Compensator," CIGRE, Working group 14.19, 1998.

[3] Laszlo Gyugyi, Colin D. Schauder, and Kalyan K. Sen, "static synchronous series compensator: a solid-state approach to the series compensation of transmission lines", IEEE Transactions on power delivery, Vol. 12, No. 1, January 1997.

[4] Vaishali M. More, V.K. Chandrakar, "Power system performances improvement by using static synchronous series compensator", international conference on Advances in Electrical, Electronics, Informantion, Communication and BioInformatics 978-1-4673-9745-2C2016 IEEE.

[5] M. Farhani, "Damping of subsynchronous oscillations in power system by using static synchronous series compensator",IET Genr. Distrib.vol.6.Iss.6.pp.539-544,2012. 
[6] C.Udhaya Shankar, Rani Thottungal, S.Mythili, "Voltage stability improvement and power oscillations damping using static synchronous seriescompensator (SSSC)", IEEE sponsored $9^{\text {th }}$ International Conference on intelligent system and control (ISCO) 2015.

[7] D.M.Holey, V.K.Chandrakar,"Dynamic harmonic domain modeling of space vector based SSSC", Energy and Power Engineering, 8, 152-160,2016.

[8] Devendra Manikrao Holey, Vinod Kumar Chandrakar, “ Dynamic harmonic domain modelling of space vector based UPFC",American Journal of Electrical Power and Energy Systems 5(1): 1-10,2016.

[9] Jiang Xu, Xiao Xiangning, Zhao Yang, Ren Aiping, "Study on main circuit selection and single phase SVPWM algorithm of SSSC", International Conference on Power System Technology 2006.

[10] Wei Xu, Xiangning Xiao, Jinmeng Chen, "Simulation and realization of closed loop control system of SSSC on RTDS",china international conference on electricity distribution 2010.

[11] K. K. Sen "SSSC - Static Synchronous Series Compensator: Theory, Modeling, and Applications", IEEE Transactions on Power Delivery, Vol. 13, No. 1, pp. 241 - 246, January 1998.

[12] R. Mihalic, and I. Papic "Mathematical Models and Simulation of a Static Synchronous Series Compensator",IEEE Power Tech'99 Conference, BPT99-315-42, August 1999. Budapest, Hungary.

[13] L. Sunil Kumar and A. Ghosh, "Modeling and control design of a static synchronous series compensator," IEEE Trans. Power Del., vol. 14, no. 4, pp. 1448-1453, Oct. 1999.

[14] R. Mohan and R. K. Varma, Thyristor-Based FACTS Controllers for Electrical Transmission Systems. Piscataway, NJ: IEEE Press, 2002. 